\title{
PERSEPSI AUDITOR DAN MAHASISWA AKUNTANSI \\ TENTANG FUNGSI MICROSOFT EXCEL YANG DIBUTUHKAN UNTUK BERKARIR SEBAGAI AUDITOR \\ (STUDI PADA BPK RI PERWAKILAN PROVINSI SULUT DAN FEB UNSRAT)
}

\author{
Weni Cikita Kuyotok $^{1}$, Harijanto Sabijono ${ }^{2}$, Victorina Z. Tirayoh ${ }^{3}$ \\ ${ }^{1,2,3}$ Jurusan Akuntansi, Fakultas Ekonomi dan Bisnis, Universitas Sam Ratulangi, Jl. Kampus Bahu, Manado, \\ 95115, Indonesia \\ E-mail : wenee.chikita@gmail.com
}

\begin{abstract}
Computer technology is very helpful in the work, one of which is microsoft excel. This study aims to determine which functions of microsoft excel that always used, considered important and need to be mastered for a career as an auditor. The object of research in this research is BPK RI Representative of North Sulawesi Province and Faculty of Economics and Business of Sam Ratulangi University. The method of analysis used in this study is descriptive analysis whose purpose each data collected analyzed and then drawn a conclusion, the type of research used is descriptive quantitative. The results of this study indicate that the basic functions, formats function and filters and sorting data is a function that is always used by auditors. Further basic functions, filter and sorting data, format functions, and keyboard shortcuts are a very important function for the auditor. Finally basic functions, filter and sorting data, format functions and keyboard shortcuts are functions that are highly controlled by auditors. Just keep in mind that for the level of importance, there is a difference between the perceptions of junior team auditors and senior team auditors. The difference is that only senior team auditors think that keyboard shortcuts are a very important function, while junior team auditors think that keyboard shortcuts are limited to important functions only. For accounting students only keyboard shortcuts which is a function that is always used. Furthermore there are six functions that are considered very important by accounting students are basic functions, keyboard shortcuts, format functions, charts and graphs, filter and sorting data, and financial functions. Recent functions that are highly controlled by accounting students are basic functions, keyboard shortcuts and format functions.
\end{abstract}

Keywords: Functions of Microsoft Excel, Auditor, Students

\section{PENDAHULUAN}

Seiring perkembangan dunia bisnis yang semakin kompleks tentunya membuka suatu bidang maupun peluang pekerjaan yang baru bagi masyarakat. Hal ini tentunya akan memudahkan para mahasiswa setelah lulus nanti dalam memilih dan menentukan pilihan karir yang akan diambil. Bagi mahasiswa akuntansi dan lulusan akuntansi, profesi auditor masih menjadi salah satu pilihan utama dalam memilih dan mengembangkan karir.

Mahasiswa akuntansi yang nantinya akan berprofesi sebagai seorang akuntan, baik itu profesi auditor internal, auditor pemerintah maupun akuntan publik, diharapkan untuk selalu mengasah kemampuan agar bisa menjadi akuntan yang baik dan profesional, agar bisa menghadapi berbagai masalah dan kasus terkait akuntansi seiring perkembangan dunia bisnis. Oleh karena itulah seorang mahasiswa akuntansi dan bahkan yang sudah menjadi seorang akuntan selalu dituntut untuk terus mengasah dan mengembangkan kemampuan untuk menghadapai berbagai tantangan pekerjaan.

Entitas yang mengelola keuangan negara yang nantinya akan diaudit oleh auditor ekternal pemerintah tidaklah sedikit, dan terdiri dari berbagai jenis usaha. Sehingga 
diharapkan bagi auditor untuk menguasai banyak pengetahuan mengenai berbagai jenis laporan keuangan. Selain menguasai pengetahuan mengenai laporan keuangan, auditor juga harus memperhatikan regulasi yang ada, karena seorang auditor harus memastikan bahwa informasi laporan keuangan suatu entitas sudah sesuai dengan regulasi yang berlaku.

Kavanagh dan Drennan (2008) menyatakan pengetahuan teoritis tentang akuntansi saja dianggap tidak cukup untuk menjadi seorang akuntan yang baik. Analytical skill, interpersonal skill, technical skill, maupun kemampuan lainnya yang relevan dengan akuntansi perlu dikuasai oleh seorang akuntan. Penelitian ini penting untuk auditor secara umum dan mahasiswa akuntansi secara khusus, dikarenakan microsoft excel merupakan salah satu software yang sangat membantu dalam pekerjaan seorang auditor. Oleh sebab itu, penelitian ini untuk mencari tahu persepsi auditor dan mahasiswa akuntansi tentang fungsi microsoft excel apa saja yang dibutuhkan untuk berkarir sebagai auditor, untuk memberikan informasi, gambaran dan pengetahuan untuk auditor dan untuk mahasiswa akutansi dalam menghadapi dunia kerja khususnya bagi mahasiswa yang ingin menjadi seorang auditor.

\section{TINJAUAN PUSTAKA}

\subsection{Pengertian Microsoft Excel}

Microsoft office excel atau microsoft excel adalah sebuah aplikasi berbentuk lembar kerja (spreadsheet) elektronik hasil besutan perusahaan Microsoft. Microsoft excel bisa digunakan dalam operating system microsoft windows maupun mac OS. Kusrianto (2014) menyatakan microsoft. excel adalah aplikasi paling canggih yang sering digunakan untuk memudahkan kegiatan dan memenuhi kebutuhan administrasi perkantoran sehari-hari. Microsoft Excel bisa diandalkan untuk memenuhi kebutuhan mulai dari melakukan kalkulasi (berbagai macam perhitungan matematika dan logika), perhitungan terkait data waktu dan tanggal, mengolah dan menampilkan data ke dalam sebuah tabel database, melakukan perhitungan dengan menggunakan fungsi-fungsi logika hingga pengolahan data dalam bentuk teks.

\subsection{Keterampilan (skill) yang Perlu Dikuasai Auditor Eksternal Pemerintah}

Dalam berkarir sebagai auditor, diharapkan seorang auditor dapat selalu meningkatkan keterampilan yang dimilik, selain menguasai pengetahuan secara teoritis, keterampilan dari auditor juga sangat perlu untuk ditingkatkan, sebagai bekal dalam melakukan tugas sebagai seorang auditor. Mengingat perekonomian yang terus berkembangan, membuat jasa auditor lebih banyak digunakan.

Menurut Cory dan Pruske (2012) yang melakukan penelitian kepada profesi akuntan maupun non akuntan, menyebutkan kedua profesi diatas sepakat bahwa setidaknya ada delapan kategori skill yang harus dikuasai dengan baik oleh mahasiswa akuntansi. Delapan kategori skill tersebut yaitu : 1) menguasai aplikasi spreadsheet (Microsoft Excel); 2) aplikasi pengolah kata (Microsoft Word); 3) kreativitas dalam menyelesaikan sebuah masalah; 4) menguasai system operasi Windows; 5) selalu memperhatikan masalah etika; 6) bisa melakukan penelitian/riset melalui internet; 7) menguasai aplikasi presentasi (Microsoft Powerpoint); 8) menguasai aplikasi pengolah database (Microsoft Access).

\subsection{Fungsi Microsoft Excel yang Perlu Dikuasai oleh Auditor}

Dalam mengoperasikan aplikasi microsoft excel tentunya tidak terlepas dari penggunaan fungsi dan rumus, apalagi jika menyangkut perhitungan (komputansi). Aplikasi microsoft excel memiliki banyak fitur yang dapat digunakan untuk mengolah data komputansi (Musliadi, 2013). Ragland dan Ramachandran (2014) telah melakukan penelitian untuk mengetahui fungsi microsoft excel manakah yang selalu digunakan, dianggap penting dan perlu dikuasai oleh akuntan publik. Penelitian mereka dilakukan dengan dua langkah. Penelitian yang pertama dilakukan dengan metode pilot survey, dimana mereka melakukan survei kepada para associates yang bekerja di dua KAP big four untuk menentukan fungsi 
microsoft excel yang dianggap penting oleh akuntan publik. Hasil dari pilot survey mereka menunjukkan ada 14 (empat belas) kelompok fungsi (maupun fitur) yang perlu dikuasai oleh akuntan publik. Empat belas fungsi tersebut yaitu:

1. Fungsi dasar, Fungsi basic dalam microsoft excel yang digunakan untuk menghitung hasil penjumlahan, perkalian, pembagian dan lain-lain. Contohnya, Fungsi SUM untuk penjumlahan dan fungsi AVERAGE untuk menghitung rata-rata.

2. Fungsi format, Fungsi dan/atau fitur microsoft excel yang digunakan untuk merubah berbagai format data yang ada di dalam Sel. Contohnya: merubah currency data, merubah jenis dan ukuran huruf, menambahkan dan menghapus border, fitur wrap text, dan lain sebagainya.

3. Fungsi filter dan sortir data, fungsi yang digunakan untuk mensortir maupun menyaring data. Contohnya: fungsi ascending dan descending untuk mengurutkan data dari yang paling besar atau dari yang paling kecil, fitur Sort By dan Sort On, dan fungsi filter untuk menampilkan data dengan kriterie tertentu.

4. Macro, fitur dalam microsoft excel yang digunakan untuk mengotomatisasi data yang berupa perintah dalam bentuk script dalam format Visual Basic (VB).

5. Fungsi Lookup, fungsi yang digunakan untuk menetukan rentang yang berisi nilai yang ingin dicocokkan, dimana fungsi ini memiliki dua bentuk yakni bentuk vector dan bentuk array. Contohnya: fungsi HLOOKUP dan fungsi VLOOKUP.

6. Pivot Table, fitur microsoft excel untuk membantu memudahkan melihat ringkasan data berupa tabel interaktif yang padat informasi dan bisa dilengkapi dengan diagram.

7. Audit Formulas, fitur microsoft excel yang digunakan untuk melacak kesalahan fungsi maupun rumus yang digunakan. Contohnya: fitur Show Formula untuk memperlihatkan formula di setiap $\mathrm{Sel}$ dan fitur error checking yang digunakan untuk memeriksa rumus yang salah.

8. Analysis Data Add-ins, fitur tambahan (Add-in) dalam microsoft excel yang bisa diaktifkan untuk digunakan dalam menganalisis data dan merupakan bagian dari Analysis Toolpak.

9. Statistical Regression Analysis, fungsi microsoft excel yang digunakan untuk menghitung dan menganalisis regresi data serta merupakan bagian dari fitur tambahan Analysis data Add-in.

10. Fungsi Concatenate, Fungsi microsoft excel yang digunakan untuk menggabungkan beberapa data teks menjadi satu teks. Contohnya: $=$ Concatenate $($ Teks1, Teks2,...)

11. Fungsi Keuangan, Fungsi yang digunakan untuk menghitung kelayakan investasi, penyusutan aktiva tetap, surat berharga, dan menghitung pinjasman (angsuran beserta bunga). Contohnya: Fungsi FV untuk mencari nilai investasi masa depan, Fungsi IRR untuk mencari tingkat pengembalian, dan Fungsi NPV untuk mencari nilai bersih saat ini dari sebuah investasi.

12. Pernyataan IF/THEN, Fungsi logika ini digunakan untuk menjalankan perintah dimana terdapat satu atau dua kondisi tertentu dengan hasil yang berbeda-beda. Fungsi IF/THEN biasanya digunakan dalam Fitur MACRO.

13. Keyboard Shortcuts, tombol atau kombinasi tombol pada keyboard yang digunakan untuk menggantikan serentetan langkah yang perlu dilakukan untuk menjalankan fitur microsoft excel agar bisa menghemat waktu dan tenaga. Contohnya: kombinasi $\mathrm{Ctrl}+\mathrm{N}$ untuk membuat workbook baru dan $\mathrm{Ctr}+\mathrm{C}$ untuk mengcopy sel, range, atau objek terpilih.

14. Diagram dan grafik, Fitur microsoft excel yang digunakan untuk membantu menyajikan data secara visual dengan bentuk diagram atau grafik.

Selanjutnya dalam penelitian yang kedua, dari 14 kelompok fungsi yang telah ada, dilakukan survey kembali kepada 113 akuntan publik yang bekerja di empat KAP besar 
untuk menentukan peringkat keempat belas fungsi tersebut dimana peringkat pertama merupakan fungsi yang paling penting dan sering digunakan, sampai peringkat terakhir yang merupakan fungsi yang paling jarang digunakan.

\subsection{Penelitian Terdahulu}

Beberapa penelitian terdahulu yang penulis jadikan sebagai bahan pertimbangan dalam melakukan penelitian ini. Penelitian yang dilakukan oleh Ragland dan Ramachandran (2014) tentang "Towards an understanding of excel functional skills needed for a career in public accounting: Perceptions from public accountants and accounting students", menyatakan bahwa akuntan yang bekeja di KAP mereka teliti percaya bahwa fungsi excel yang paling penting adalah fungsi dasar, filter and sortir data, lookup, fungsi format, dan pernyataan If/Then. Sedangkan untuk mahasiswa akuntansi meremehkan pentingnya penggunaan fungsi-fungsi tersebut. Pada penelitian yang dilakukan oleh Pratama (2015) tentang Fungsi Microsoft Excel yang Dibutuhkan Untuk Berkarir Sebagai Akuntan Publik : Persepsi dari Akuntan Publik, menyatakan bahwa fungsi dasar, fungsi format, fungsi filter dan sortir data, fungsi lookup, pivot table dan audit formula merupakan fungsi microsoft excel yang paling penting bagi akuntan publik. Selanjutnya, fungsi dasar, fungsi format, fungsi filter dan sortir data, macro, fungsi lookup, pivot table, audit formula, analysis data add-ins, statistical regression analysis, fungsi concatenate, fungsi keuangan, pernyataan IF/THEN, keyboard shortcuts, serta diagram dan grafik merupakan fungsi microsoft excel yang harus dikuasai oleh akuntan publik. Terakhir, fungsi dasar dan fungsi filter dan sortir data merupakan fungsi microsoft excel yang selalu digunakan oleh akuntan publik.

\section{METODE PENELITIAN}

\subsection{Jenis Penelitian}

Jenis penelitian yang digunakan dalam penelitian ini adalah kuantitatif deskriptif. Ulum (2011:69), menjelaskan penelitian deskriptif adalah jenis penelitian yang bertujuan untuk menjelaskan sesuatu melalui sebuah penelitian.Penelitian jenis ini hanya bertujuan untuk mendeskripsikan mengenai sesuatu, tidak bertujuan untuk melihat suatu hubungan atau membandingkan tetapi hanya menjelaskan saja. Penelitian yang peneliti lakukan ini bertujuan untuk menjelaskan persepsi auditor dan mahasiswa akhir jurusan akuntansi terhadap tingkat penggunaan, tingkat kepentingan dan tingkat penguasaan berbagai fungsi microsoft excel untuk berkarir sebagai auditor.

\subsection{Populasi dan Sampel}

\subsubsection{Populasi}

Menurut Sugiyono (2016:80), populasi adalah wilayah generalisasi yang terdiri atas objek/subjek yang mempunyai kualitas dan karakteristik tertentu yang ditetapkan oleh peneliti untuk dipelajari, kemudian ditarik kesimpulannya. Populasi dalam penelitian ini terdiri dari 2 kelompok responden. Kelompok pertama adalah seluruh auditor yang bekerja di BPK RI Perwakilan Provinsi Sulawesi Utara yang berjumlah 62 orang auditor yang di dalamnya terdapat 16 orang auditor tim junior dan 25 orang auditor tim senior, dan kelompok kedua adalah mahasiswa jurusan akuntansi semester viii yang berjumlah 379 orang mahasiswa yang berada di Fakultas Ekonomi dan Bisnis Universitas Sam Ratulangi Manado.

\subsubsection{Sampel}

Sugiyono (2016: 215) mendefinisikan sampel sebagai bagian dari jumlah dan karakteristik yang dimiliki oleh populasi. Dalam menentukan jumlah sampel, peneliti menggunakan rumus Slovin. Rumus Slovin digunakan dalam penelitian ini karena populasi dalam penelitian ini memiliki homogenitas tinggi (populasi adalah auditor dan mahasiswa jurusan akuntasi semester viii), maka tidak semua populasi tersebut menjadi subjek dalam penelitian ini. Penggunaan rumus Slovin bermaksud untuk memperkecil jumlah pengambilan 
sampel agar penelitian menjadi lancar dan efisien. Perhitungan sampel menggunakan rumus Slovin sebagai berikut :

1. Perhitungan sampel untuk auditor

$$
\begin{aligned}
& \mathrm{n}=\frac{62}{1+62(0,1)^{2}} \\
& \mathrm{n}=38,271604938 \text { dibulatkan menjadi } 38 \text { orang }
\end{aligned}
$$

Dalam penelitian ini jumlah sampel untuk auditor seharunya berjumlah 38 orang auditor yang terdiri dari 16 orang auditor tim junior dan 22 orang auditor tim senior. Tetapi saat membagikan kuesioner hanya ada 30 orang auditor (yang terdiri dari 15 orang auditor tim junior dan 15 orang auditor tim senior) yang bersedia dalam mengisi kuesioner tersebut. Sedangkan untuk 8 keusioner yang lain tidak diisi oleh auditor, karena pada saat itu hanya ada 30 orang auditor yang berada di tempat. Oleh karena itu peneliti menggunakan 30 kuesioner untuk dijadikan sebagai sampel penelitian.

2. Perhitungan sampel untuk mahasiswa

$$
\begin{gathered}
\mathrm{n}=\frac{379}{1+379(0,1)^{2}} \\
\mathrm{n}=79,123173 \text { dibulatkan menjadi } 79 \text { orang }
\end{gathered}
$$

Untuk mahasiswa akuntansi, sampel yang digunakan sebanyak 79 orang mahasiswa. Selain auditor, subjek penelitian yang digunakan adalahnya mahasiswa akuntansi semester viii FEB UNSRAT. Hal ini dikarenakan pola pikir mahasiswa tersebut telah terbentuk dengan matang dalam rangka menghadapi dunia kerja profesional.

Dengan perhitungan sampel untuk masing-masing subjek penelitian di atas, dapat dilihat bahwa total sampel yang digunakan dalam penelitian ini adalah sebanyak 109 sampel.

\subsection{Model Sampling}

Dalam penentuan sampel, peneliti memutuskan untuk menggunakan teknik Purposive sampling. Purposive sampling dalam Sugiyono (2016: 85) diartikan sebagai teknik pengambilan sampel sumber data dengan pertimbangan tertentu.

\subsection{Tempat dan Waktu Penelitian}

Penelitian dilakukan pada Badan Pemeriksa Keuangan Republik Indonesia Perwakilan Provinsi Sulawesi Utara yang berlokasi di J1. 17 Agustus, No.04, Bumi Beringin, Manado, Kota Manado, Sulawesi Utara. Dan Fakultas Ekonomi Dan Bisnis Universitas Sam Ratulangi yan berlokasi di Jl. Kampus Unsrat, Bahu, Malalayang, Manado, 95115. Waktu penelitian di lakukan selama kuran lebih 1 bulan yaitu sejak bulan maret-april 2018.

\subsection{Metode dan Proses Analisis Data}

Analisis data penelitian ini dilakukan melalui proses sebagai berikut:

1. Tahap tabulasi data. Data yang telah terkumpul dilakukan tabulasi menurut persepsi auditor di BPK yang juga dibagi menjadi persepsi auditor tim senior dan auditor tim junior serta persepsi mahasiswa akuntansi semester viii FEB UNSRAT. Selain itu dilakukan juga tabulasi berdasarkan, tingkat penggunaan fungsi microsoft excel, tingkat kepentingan fungsi microsoft excel dan tingkat penguasaan fungsi microsoft excel dari kedua kelompok responden. 
2. Tahap selanjutnya adalah distribusi frekuensi yang meliputi perhitungan mean, median dan standar deviasi. Perhitungan mean sendiri dimaksudkan untuk memudahkan dalam meranking persepsi dari jawaban yang telah diberikan oleh responden.

3. Tahap selanjutnya adalah Analisis Deskriptif. Dalam tahap ini, peneliti nantinya akan memberikan deskripsi mengenai :

a. Tingkat Penggunaan dari keempat belas fungsi microsoft excel berdasarkan persepsi auditor (auditor tim senior dan tim junior) dan persepsi dari mahasiswa akuntansi mengenai penggunaan keempat belas fungsi microsoft excel dalam berkarir sebagai auditor.

b. Tingkat Kepentingan dari keempat belas fungsi microsoft excel berdasarkan persepsi auditor dan persepsi dari mahasiswa akuntansi mengenai pentingnya keempat belas fungsi microsoft excel dalam berkarir sebagai auditor.

c. Tingkat Penguasaan dari keempat belas fungsi microsoft excel berdasarkan persepsi auditor dan persepsi dari mahasiswa akuntansi mengenai penguasaan keempat belas fungsi microsoft excel dalam berkarir sebagai auditor.

4. Tahap terakhir adalah penarikan kesimpulan terkait keempat belas fungsi microsoft excel yang selalu digunakan, dianggap penting dan dikuasai oleh dua kelompok responden berdasarkan hasil analisis dari tingkat penggunaan tingkat kepentingan, dan tingkat penguasaan fungsi microsoft excel.

\section{HASIL DAN PEMBAHASAN}

\subsection{Hasil Analisis}

\subsubsection{Tingkat Penggunaan}

Tabel 4.1

Analisis Deskriptif Tingkat Penggunaan

\begin{tabular}{|c|c|c|c|}
\hline Derajat Penggunaan & & Kelompok Responden & \\
\hline & Auditor Tim Junior & Auditor Tim Senior & $\begin{array}{c}\text { Mahasiswa Akuntansi } \\
\text { Sem. VIII }\end{array}$ \\
\hline Top Level: Selalu & $\begin{array}{l}\text { 1. Fungsi Dasar } \\
\text { 2. Fungsi Format } \\
\text { 3.Fungsi Filter dan Sortir } \\
\text { Data }\end{array}$ & $\begin{array}{l}\text { 1. Fungsi Filter dan Sortir } \\
\text { Data } \\
\text { 2. Fungsi Format } \\
\text { 3. Fungsi Dasar }\end{array}$ & 1. Keyboard Shortcuts \\
\hline Middle Level: Sering & $\begin{array}{l}\text { 4. Keyboard Shortcuts } \\
\text { 5. Audit Formula } \\
\text { 6. Pivot Table } \\
\text { 7. Diagram dan Grafik } \\
\text { 8. Fungsi Lookup } \\
\text { 9. Pernyataan IF/THEN } \\
\text { 10. Fungsi Keuangan } \\
\text { 11. Analysis Data Add-in } \\
\text { 12. Statistical Regression } \\
\text { Analysis }\end{array}$ & $\begin{array}{l}\text { 4. Keyboard Shortcuts } \\
\text { 5. Pivot Table } \\
\text { 6. Audit Formula } \\
\text { 7. Fungsi } \\
\text { Lookup } \\
\text { 8. Diagram dan Grafik } \\
\text { 9. Pernyataan } \\
\text { IF/THEN } \\
\text { 10. Fungsi } \\
\text { Concatenate }\end{array}$ & $\begin{array}{l}\text { 2. Fungsi Dasar } \\
\text { 3. Fungsi Format } \\
\text { 4. Diagram } \\
\quad \text { dan } \\
\text { Grafik } \\
\text { 5. Fungsi Filter dan Sortir } \\
\text { Data } \\
\text { 6. Pernyataan IF/THEN } \\
\text { 7. Fungsi Keuangan }\end{array}$ \\
\hline $\begin{array}{c}\text { Bottom Level: Cukup } \\
\text { Sering }\end{array}$ & $\begin{array}{l}\text { 13. Fungsi Concatenate } \\
\text { 14. Macro }\end{array}$ & $\begin{array}{l}\text { 11. Macro } \\
\text { 12.AnalysisData } \\
\text { Add-in } \\
\text { 13. Statistical } \\
\text { Regression } \\
\text { Analysis } \\
\text { 14. Fungsi } \\
\text { Keuangan }\end{array}$ & $\begin{array}{l}\text { 8. Audit Formula } \\
\text { 9. Fungsi } \\
\text { Concatenate } \\
\text { 10. Pivot Table } \\
\text { 11. Analysis Data Add-in } \\
\text { 12. Macro } \\
\text { 13. Statistical Regression } \\
\text { Analysis } \\
\text { 14. Fungsi Lookup }\end{array}$ \\
\hline
\end{tabular}




\subsubsection{Tingkat Kepentingan}

Tabel 4.2

Analisis Deskriptif Tingkat Kepentingan

\begin{tabular}{|c|c|c|c|}
\hline Derajat Penggunaan & & Kelompok Responden & \\
\hline & Auditor Tim Junior & Auditor Tim Senior & $\begin{array}{c}\text { Mahasiswa Akuntansi } \\
\text { Sem. VIII }\end{array}$ \\
\hline Top Level: Sangat Penting & $\begin{array}{l}\text { 1.Fungsi Dasar } \\
\text { 2. Fungsi Filter } \\
\text { dan Sortir } \\
\text { Data } \\
\text { 3. Fungsi } \\
\text { Format }\end{array}$ & $\begin{array}{l}\text { 1. Fungsi Filter } \\
\text { dan Sortir } \\
\text { Data } \\
\text { 2. Keyboard } \\
\text { Shortcuts } \\
\text { 3. Fungsi } \\
\text { Dasar } \\
\text { 4. Fungsi } \\
\text { Format }\end{array}$ & $\begin{array}{l}\text { 1. Fungsi } \\
\text { Dasar } \\
\text { 2. Keyboard } \\
\text { Shortcuts } \\
\text { 3. Fungsi } \\
\text { Format } \\
\text { 4. Diagram dan } \\
\text { Grafik } \\
\text { 5. Fungsi Filter } \\
\text { dan Sortir } \\
\text { Data } \\
\text { 6. Fungsi } \\
\text { Keuangan }\end{array}$ \\
\hline Midle Level: Penting & $\begin{array}{l}\text { 4. Pivot Table } \\
\text { 5. Audit } \\
\text { Formula } \\
\text { 6. Fungsi } \\
\text { Lookup } \\
\text { 7. Keyboard } \\
\text { Shortcuts } \\
\text { 8. Pernyataan } \\
\text { IF/THEN } \\
\text { 9. Diagram dan } \\
\text { Grafik } \\
\text { 10. Fungsi } \\
\text { Keuangan } \\
\text { 11. Statistical } \\
\text { Regression } \\
\text { Analysis } \\
\text { 12. Macro } \\
\text { 13. Analysis } \\
\text { Data Add-in }\end{array}$ & $\begin{array}{l}\text { 5. Pivot Table } \\
\text { 6. Audit } \\
\text { Formula } \\
\text { 7. Fungsi } \\
\text { Lookup } \\
\text { 8. Diagram dan } \\
\text { Grafik } \\
\text { 9. Analysi } \\
\text { Data Add-in } \\
\text { 10. Pernyataan } \\
\text { IF/THEN } \\
\text { 11. Macro } \\
\text { 12. Fungsi } \\
\text { Concatenate }\end{array}$ & $\begin{array}{l}\text { 7. Audit } \\
\text { Formula } \\
\text { 8. Pernyataan } \\
\text { IF/THEN } \\
\text { 9. Analysis } \\
\text { Data Add-In } \\
\text { 10. Fungsi Concatenate } \\
\text { 11. Pivot Table }\end{array}$ \\
\hline $\begin{array}{l}\text { Bottom Level: Cukup } \\
\text { Penting/Pelengkap }\end{array}$ & 14. Fungsi Concatenate & $\begin{array}{l}\text { 13. Statistical } \\
\text { Regression } \\
\text { Analysis } \\
\text { 14. Fungsi } \\
\text { Keuangan }\end{array}$ & $\begin{array}{l}\text { 12. Statistical } \\
\text { Regression } \\
\text { Analysis } \\
\text { 13. Macro } \\
\text { 14. Fungsi } \\
\text { Lookup }\end{array}$ \\
\hline
\end{tabular}




\subsubsection{Tingkat Penguasaan}

Tabel 4.3

Analisis Deskriptif Tingkat Penguasaan

\begin{tabular}{|c|c|c|c|}
\hline Derajat Penggunaan & & Kelompok Responden & \\
\hline & Auditor Tim Junior & Auditor Tim Senior & $\begin{array}{c}\text { Mahasiswa Akuntansi } \\
\text { Sem. VIII }\end{array}$ \\
\hline $\begin{array}{c}\text { Top Level: Sangat } \\
\text { Menguasai }\end{array}$ & $\begin{array}{l}\text { 1. Fungsi } \\
\text { Dasar } \\
\text { 2. Fungsi Filter } \\
\text { Dan Sortir } \\
\text { Data } \\
\text { 3. Fungsi } \\
\text { Format } \\
\text { 4. Keyboard } \\
\text { Shortcuts } \\
\end{array}$ & $\begin{array}{l}\text { 1. Fungsi Filter } \\
\text { dan Sortir } \\
\text { Data } \\
\text { 2. Fungsi } \\
\text { Format } \\
\text { 3. Fungsi } \\
\text { Dasar } \\
\text { 4. Keyboard } \\
\text { Shortcuts } \\
\end{array}$ & $\begin{array}{l}\text { 1. Fungsi } \\
\text { Dasar } \\
\text { 2. Keyboard } \\
\text { Shortcuts } \\
\text { 3. Fungsi } \\
\text { Format }\end{array}$ \\
\hline Middle Level: Menguasai & $\begin{array}{l}\text { 5. Pernyataan } \\
\text { IF/THEN } \\
\text { 6. Diagram dan } \\
\text { Grafik } \\
\text { 7. Pivot Table } \\
\text { 8. Fungsi } \\
\text { Lookup } \\
\text { 9. Fungsi } \\
\text { Keuangan } \\
\text { 10. Audit } \\
\text { Formula } \\
\text { 11. Analysis } \\
\text { Data Add-in } \\
\text { 12. Statistical } \\
\text { Regression } \\
\text { Analysis } \\
\text { 13. Macro }\end{array}$ & $\begin{array}{l}\text { 5. Pivot Table } \\
\text { 6. Pernyataan } \\
\text { IF/THEN } \\
\text { 7. Diagram dan } \\
\text { Grafik } \\
\text { 8. Audit } \\
\text { Formula } \\
\text { 9. Fungsi } \\
\text { Lookup } \\
\text { 10. Fungsi } \\
\text { Keuangan } \\
\text { 11. Analysis } \\
\text { Data Add-in } \\
\text { 12. Statistical } \\
\text { Regression } \\
\text { Analysis } \\
\text { 13. Fungsi } \\
\text { Concatenate }\end{array}$ & $\begin{array}{l}\text { 4. Fungsi } \\
\text { Filter dan } \\
\text { Sortir Data } \\
\text { 5. Diagram dan Grafik } \\
\text { 6. Pernyataan IF/THEN } \\
\text { 7. Fungsi Concatenate }\end{array}$ \\
\hline $\begin{array}{c}\text { Bottom Level: Cukup } \\
\text { Menguasai }\end{array}$ & $\begin{array}{l}\text { 14. Fungsi } \\
\text { Concatenate }\end{array}$ & 14. Macro & $\begin{array}{l}\text { 8. Fungsi Keuangan } \\
\text { 9. Audit Formula } \\
\text { 10. Analysis Data Add-in } \\
\text { 11. Pivot Table } \\
\text { 12. Statistical Regression } \\
\text { Analysis } \\
\text { 13. Macro } \\
\text { 14. Fungsi Lookup }\end{array}$ \\
\hline
\end{tabular}

\subsection{Pembahasan}

\subsubsection{Tingkat Penggunaan}

Dari tabel tingkat penggunaan di atas kita bisa mengetahui bahwa untuk auditor tim junior, fungsi yang selalu digunakan adalah fungsi dasar, fungsi format dan fungsi filter dan sortir data. Hasil ini dikarenakan sebagai auditor tim junior yang baru saja memasuki dunia praktik auditing, dan mulai familiar menggunakan microsoft excel sebagai alat bantu pekerjaan, sehingga memerlukan pengetahuan yang memadai dalam mengoperasikan fungsi dasar microsoft excel. Untuk level auditor tim senior, fungsi yang selalu digunakan adalah fungsi filter dan sortir data, fungsi format dan fungsi dasar yang merupakan kebalikan dari fungsi-fungsi yang selalu digunakan oleh auditor tim junior. Hasil ini dikarenakan auditor tim senior hanya menggunakan fungsi-fungsi yang membantu dalam mensupervisi pekerjaan dari auditor tim junior. Perbedaan muncul pada persepsi mahasiswa akuntansi, dimana fungsi yang selalu digunakan menurut mahasiswa akuntansi adalah keyboard shortcuts. Hasil ini 
dikarenakan mahasiswa akuntansi yang selalu menggunakan keyboard shortcut dalam mengoperasikan berbagai software microsoft dan fungsi ini juga dianggap paling mudah untuk digunakan.

\subsubsection{Tingkat Kepentingan}

Dari tabel tingkat kepentingan diatas kita bisa mengetahui bahwa berdasarkan tingkat kepentingan bagi auditor tim junior, fungsi dasar, fungsi filter dan sortir data, dan fungsi format merupakan fungsi yang sangat penting. Jika dilihat pada tingkat penggunaan auditor tim junior, fungsi yang selalu digunakan sama dengan fungsi yang dianggap sangat penting oleh auditor tim junior. Dikarenakan selalu digunakan dalam pekerjaan, maka fungsi-fungsi itulah yang sangat penting.

Bagi auditor tim senior, fungsi yang sangat penting adalah fungsi filter dan sortir data, keyboard shortcuts, fungsi dasar, dan fungsi format. Hasil ini dikarenakan fungsi-fungsi tersebut adalah fungsi yang membantu dalam mensupervisi pekerjaan dari auditor tim junior, oleh karena itu fungsi-fungsi tersebut dianggap sanggat penting. Bagi mahasiswa akuntansi, fungsi dasar, keyboard shortcuts, fungsi format, diagram dan grafik, fungsi filter dan sortir data, dan fungsi keuangan merupakan fungsi yang sangat penting. Hasil ini dikarenakan fungsi-fungsi tersebut merupakan fungsi yang familiar untuk mahasiswa akuntansi, oleh sebab itu dianggap penting oleh mahasiswa.

\subsubsection{Tingkat Penguasaan}

Berdasarkan tabel tingkat penguasaan diatas kita bisa mengetahui bahwa fungsi dasar, fungsi filter dan sortir data, fungsi format dan keyboard shortcuts merupakan fungsi yang sangat dikuasai oleh auditor tim junior. Hasil ini dikarenakan fungsi dasar, fungsi filter dan sortir data, fungsi format merupakan fungsi yang selalu digunakan dan dianggap sangat penting oleh auditor tim junior, karena selalu digunakan dan dianggap penting maka fungsi tersebut sangat dikuasai oleh auditor tim junior. Namun beda halnya dengan keyboard shortcuts. Meskipun fungsi ini sangat dikuasai, tetapi fungsi ini hanya sebatas fungsi pelengkap dalam pekerjaan. Fungsi tersebut juga ternyata tidak selalu digunakan, tetapi sebatas cukup sering digunakan untuk membantu pekerjaan.

Menurut pendapat auditor tim senior fungsi yang sangat dikuasai adalah fungsi filter dan sortir data, fungsi format, fungsi dasar, keyboard shortcuts, sependapat dengan auditor tim junior tetapi ada perbedaan dalam urutannya. Hasil ini dikarenakan fungsi filter dan sortir data, fungsi format, fungsi dasar merupakan fungsi yang selalu digunakan dan dianggap sangat penting oleh auditor tim senior. Karena selalu digunakan dan dianggap sangat penting maka fungsi tersebut sangat dikuasai oleh auditor tim senior. Namun untuk keyboard shortcut, meskipun fungsi ini dianggap sangat penting dan sangat dikuasai oleh auditor tim senior, tetapi fungsi ini tidak selalu digunakan dalam pekerjaan. Menurut mahasiswa akuntansi, fungsi yang sangat dikuasai hanya ada 3 fungsi, yaitu fungsi dasar, keyboard shortcuts dan fungsi format. Hasil ini dikarenakan menurut mahasiswa akuntansi ketiga fungsi tersebut merupakan fungsi yang paling mudah untuk dipelajari.

\section{KESIMPULAN DAN SARAN}

\subsection{Kesimpulan}

Kesimpulan yang bisa diambil oleh peneliti dari penelitian ini adalah pertama, berdasarkan tingkat penggunaan, bagi auditor tim junior, fungsi dasar, fungsi format dan fungsi filter dan sortir data merupakan fungsi microsoft excel yang selalu digunakan. Bagi auditor tim senior, fungsi filter dan sortir data, fungsi format, dan fungsi dasar merupakan fungsi microsoft excel yang selalu digunakan. Bagi mahasiswa akuntansi, hanya keyboard shortcuts yang selalu digunakan dalam mengoperasikan microsoft excel sebagai alat bantu pekerjaan. 
Kedua, berdasarkan tingkat kepentingan, fungsi dasar, fungsi filter dan sortir data, dan fungsi format merupakan fungsi yang sangat penting oleh auditor tim junior. Untuk auditor tim senior, pendapatnya sejalan dengan auditor tim junior hanya saja ditambah dengan keyboard shortcuts. Untuk mahasiswa akuntansi, ada enam fungsi yang dianggap penting, yakni fungsi dasar, keyboard shortcuts, fungsi format, diagram dan grafik, fungsi filter dan sortir data, dan fungsi keuangan.

Ketiga, berdasarkan tingkat penguasaan, fungsi microsoft excel yang sangat dikuasai oleh auditor tim senior dan auditor tim senior adalah fungsi dasar, fungsi filter dan sortir data, fungsi format dan keyboard shortcuts. Sedangkan untuk mahasiswa akuntansi, fungsi dasar, keyboard shortcuts dan fungsi format merupakan fungsi microsoft excel yang sangat dikuasai.

\subsection{Saran}

Peneliti menyarankan untuk penelitian selanjutnya agar memperhatikan peak season dari auditor yang bekerja di BPK sehingga jika menggunakan kuesioner, kuesionernya bisa diterima oleh pihak BPK dengan jumlah yang diharapkan. Untuk penelitian selanjutnya yang ingin menyadur atau mengadopsi item pertanyaan dalam penelitian ini, peneliti menyarankan untuk lebih detail lagi dalam menjelaskan konsep-konsep dari masing-masing fungsi microsoft excel agar lebih mudah dimengerti oleh responden, sehingga mendapatkan jawaban yang dapat diterima. Diharapkan juga untuk penelitian sebelumnya agar bisa memperluas wilayah penelitian, tidak hanya melakukan penelitian di BPK RI Provinsi Sulawesi Utara dan Fakultas Ekonomi dan Bisnis Universitas Sam Ratulangi.

\section{DAFTAR PUSTAKA}

Arens, A.A., R.J. Elder, dan M.S. Beasley. 2015. Auditing Dan Jasa Assurance. Edisi Kelimabelas. Jilid 1. Ahli bahasa Herman Wibowo dan Tim Perti. Jakarta: Erlangga

Cory, S.N., dan K.A. Pruske. 2012. Necessary skills for accounting graduates: An exploratory study to determine what the profession wants. Journal. Proceeds of ASBBS Annual Conference: Las Vegas, 19.

Drew, J. 2012. Technology and CPAs: Visions of the Future. Journal of Accountancy.(http://www.journalofaccountancy.com/issues/2012/jun/20114844.html) diakses tanggal 19 Januari 2018

Enterprise, Jubilee. 2015. VBA Macro MS Excel Manual Book. Jakarta: Penerbit PT Elex Media Komputindo.

Iqbal, S. 2005. Persepsi Profesi Akuntansi: Pengetahuan Teknologi Informasi Yang Harus Dikuasai. Jurnal. Departemen Akuntansi Fakultas Ekonomi Universitas Brawijaya. Malang

Kavanagh, M.H dan Drennan, L. 2008. What Skills and Attributes Does and Accounting Graduate Need? Evidence from Student Perception and Employer Expectations. Journal. Accounting and Finance.

Kusrianto, A. 2014. Mengaplikasikan Formula dan Fungsi Excel 2007-2013. Jakarta : PT Elex Media Komputindo.

Pratama, Yusuf. 2015. Fungsi Microsoft Excel yang Dibutuhkan Untuk Berkarir Sebagai Akuntan Publik: Persepsi Dari Akuntan Publik. Jurnal. Fakultas Ekonomi dan Bisnis Universitas Brawijaya. Malang.

Putra, M.B.P. 2013. Pemilihan Karier Akuntan Publik: Pengaruh Orientasi Etika, Gender, Umur dan Tingkat Pengetahuan. Skripsi. Fakultas Ekonomi dan Bisnis Universitas Brawijaya. Malang. 
Ragland, L., dan U. Ramachandran. 2014. Towards an understanding of excel functional skills needed for a career in public accounting : Perceptions from public accountants and accounting students. Journal of Accounting Education (32). USA : Elsevier Ltd.

Ulum, I. 2011. Klinik Skripsi : Jurus-jurus Jitu Menyusun Skripsi dan PKM. Malang: Aditya Media Publishing.

Widarno, B. 2007. Profil dan Kompetensi Sarjana Akuntansi. Jurnal Ekonomi dan Kewirausahaan Vol. 7. 